\title{
TENSIONES EN TORNO A LA TRANSMISIÓN DE MEMORIAS VINCULADAS AL CONFLICTO ARMADO EN COLOMBIA
}

Yomaira García-Acuña*

\footnotetext{
* Psicóloga. Docente-Investigadora de la Universidad Simón Bolívar. Miembro de los Grupos "Derechos Humanos, Cultura de paz, conflicto y Postconflicto" y "Estudios de Género, Familias y Sociedad". ygarcia1@unisimonbolivar.edu.co
} 


\section{INTRODUCCIÓN}

Frente a la finalización de los diálogos en La Habana y la firma de los acuerdos, dentro de lo que se viene llamando Proceso de $\mathrm{Paz}$, se han venido considerando propuestas sobre lo que sería un país sin conflicto armado. Se espera que surjan nuevas miradas a las víctimas y que sus anhelos, en términos de verdad, justicia y reparación, dejen de ser lemas y se avance hacia realidades. Sin embargo, ante lo prolongado del conflicto armado, y sus recomposiciones, así como al surgimiento y convivencia con otras formas de violencia, subsiste un optimismo moderado sobre los reales efectos de la firma y los avances que se puedan dar para el establecimiento de una Comisión de la Verdad y aún más, sus efectos.

En trabajos anteriores abordamos el tema de las memorias, destacando los desarrollos que ha tenido el tema en nuestro país y señalando el importante papel que tienen las familias en los procesos de recordar (Ver, García, 2012a, 2012b, 2015). En este artículo, retomamos algunos de los resultados de esos trabajos y continuamos avanzando en el cuestionamiento del papel que cumplen los colectivos de víctimas, familiares en su mayor parte, en esos procesos, particularmente en el sentido de las transformaciones que necesita nuestro país.

Partimos del reconocimiento, que a pesar de que se está hablando de memorias y se ha escrito bastante acerca del tema de violencia por razones del conflicto armado, no podemos pensar que un fenómeno del cual se habla en alto grado, es porque hay claridad sobre el mismo. William Ospina (2001, p.221), poeta colombiano, se refiere a este aspecto y cita a Milan Kundera, quien señaló "que un fenómeno puede ser advertido con más 
claridad y en todas sus manifestaciones y consecuencias cuando apenas se insinúa, que cuando ya nos rodea por todas partes".

Por lo anterior, lo que me propongo en este capítulo es analizar algunos fundamentos de los procesos de transmisión y particularmente las tensiones que se generan en la construcción de lazos sociales que posibiliten avanzar hacia un país menos violento. Un punto de partida es el sentido que se le da al pasado y a las experiencias de sufrimiento, el cual nos permite en segunda instancia pasar a la reflexión acerca del tema de transmisión y finalmente, revisar en el marco del conflicto armado el papel que para los efectos de los trabajos de memoria, tienen las familias y su vinculación con los derechos económicos, políticos y culturales

\section{LA PREOCUPACIÓN POR EL PASADO Y LAS EXPERIENCIAS DE SUFRIMIENTO}

Iniciamos con la expresión de Maurice Halbwachs (2004, p.68): Por lo demás, aparte de los grabados y libros, en la sociedad actual, el pasado ha dejado muchas marcas, a veces visibles, que percibimos tambien en la expresión de sus rostros, en el aspecto de los lugares e incluso en las formas de pensar y sentir, conservadas inconscientemente y reproducidas por ciertas personas y en ciertos medios.

Pero como señala Régine Robin (2012), este pasado no es libre, es regido, administrado, conservado, explicado, narrado, conmemorado, u odiado. Ya sea que se lo celebre u oculte es un desafío para el presente. También decimos es usado, de ahí la expresión 'usos públicos del pasado' y más aún como el título del texto de Enzo Traverso (2007), El pasado instrucciones de su uso. 
Por ello la importancia de la concepción de archivo tal como la trabaja Alejandro Castillejo (2009, p.306), quien anota que al nombrar la violencia se hace un ejercicio de archivar y define este como una serie de operaciones conceptuales y políticas por medio de las cuales se autoriza, se domicializa -en coordenadas espaciales y temporales- se consigna, se codifica y se nombra el pasado en cuanto tal. Este ejercicio es análogo al ejercicio de producir un mapa*. Así mismo aclara, que identificar y autorizar el pasado requiere de una matriz interpretativa, una mirada y oídos calibrados para aprehender una serie de experiencias e incorporarlos en un corpus. Por su parte, consignar se refiere no a situar objetos en un lugar, sino a agrupar semióticamente, por ello se puede hablar de voluntad de consignación. Archivar es por tanto asignar sentido en la medida en que el pasado es nombrado.

Pero el pasado no es estático, se actualiza de manera permanente, se resignifica, ya sea por efecto del transcurso del tiempo en sí mismo o la acción de emprendedores ${ }^{\dagger}$, esto es, personas que hacen gestión acerca de algún suceso o nuevas generaciones que interrogan el pasado dándole otro sentido a lo vivido por ellos directamente, o recibido a través del diálogo con otros y otras. $Y$ este relato no se compone de hechos sino de experiencias y es un ejercicio situado, de acuerdo a Martínez (2011).

Ese pasado puede leerse de otra manera, por efecto de las reinterpretaciones que la academia, la cooperación internacional, así como desde lo gubernamental introducen. En este sentido,

\footnotetext{
* En el mismo texto (2009, p.66) puede leerse lo que implica mapear: representar, clasificar, nombrar y codificar.

† Tomo el término emprendedores como lo utiliza Jelin (2002).
} 
podemos mencionar como ejemplo lo establecido en la Ley 1448 , Ley de víctimas y Restitución de tierras, donde para efectos de reparación solo se reconocen las víctimas a partir de 1985; este recorte al mismo tiempo que invisibiliza otras víctimas, da otras lecturas al conflicto y anula la interpretación de otras formas estructurales de violencia y con una vigencia mayor.

¿Dónde queda lo que tanto se ha insistido: 60 años de conflicto armado, punto que señalamos en la introducción? Varios son los cuestionamientos que surgen con relación al uso que se le da al pasado. Es así como Iván Cepeda Castro (2007), Defensor de Derechos Humanos y coordinador del Movimiento Nacional de Víctimas de Crímenes de Estado, MOVICE, anota que a pesar de los efectos tan evidentes de la violencia, se observa una falta de reconocimiento y desconocimiento sobre esta situación a nivel de la sociedad en general. Por esto propone que es la sociedad la que necesita recordar y no las víctimas, porque la vida de estas ya está inmersa en la victimización.

Se esperaría entonces, que frente a 60 años de conflicto armado, la sociedad en general estuviese más sensibilizada, fuese más solidaria con los otros y otras que han sufrido de manera directa, por asesinatos de personas cercanas, secuestros, expulsión y huida de sus territorios $u$ otras acciones. Sin embargo esto no ha sido así. Una memoria banal tendría una gran parte de los colombianos y colombianas, como lo señalaron -para el caso de ChileLechner y Güell (2006); esto es una memoria no dramática, que no ha sufrido muertes pero tampoco las ignora. Memoria con miedos cotidianos, sin discurso legitimario, que asume lo sucedido como parte de la normalidad y con un silencio que no es pasivo. 
¿Cómo se insertan los relatos de las personas (microrrelatos) en un relato de conjunto de la sociedad? Esa es la pregunta que se hace Daniel Pécaut (2013, p.52) en su libro La experiencia de la violencia: Los desafíos del relato y la memoria.

Después de estas preocupaciones recientes, podemos retornar a lo que Maurice Halbwachs (1994) había planteado con relación al uso de los recuerdos y que lo tomamos como parte del pasado. En primer lugar destaca que los marcos no son exclusivamente individuales: son comunes a los hombres de un mismo grupo.

Pero es evidente que la violencia vinculada al conflicto armado no ha afectado a todas las personas de igual manera; de ahí que sus efectos como son las pérdidas, el sufrimiento, se distribuye de manera desigual, sucediendo lo mismo con la asignación de recursos, medidas de reparación, y en general las iniciativas de memoria, institucionales y de colectivos sociales.

Antonio Madrid (2010) en su trabajo sobre el tema del sufrimiento, considera que para que esté presente la solidaridad, comprensión, y si se quiere hermanamiento frente a los sucesos, han de darse algunas circunstancias materiales, culturales, económicas y políticas para que pueda utilizarse el sufrimiento como catalizador. Reconocerse a sí mismo en una misma experiencia colectiva, compartir objetivos e ideología y sentirse igualados en su sufrimiento, Proceso que se intensifica cuando se identifica a un tercero como el causante.

Desde las consideraciones de filósofos sobre la compasión, los desarrollos del psicoanálisis de Freud y su concepto de transferencia y empatía, hasta las concepciones más cognitivo-conduc- 
tuales enmarcadas en propuestas como "Ponerse en los zapatos del otro"*, el énfasis está puesto en esa comprensión de la experiencia.

De este concepto de experiencia se ha planteado su complejidad, aparece escasamente definido por sí solo, se lo hace con relación a otro término. Se asimila a vivencia de algo. Freud lo trabajó y Walter Benjamin (1967), anota que donde hay experiencia en el sentido propio del término, ciertos contenidos del pasado individual entran en conjunción en la memoria, con elementos del pasado colectivo (p.11). En ese mismo texto, retomando a Freud, aclara que el autor utiliza las palabras Erfahrung, que es la 'experiencia en bruto', esto es, sin la intervención de la conciencia y Erlebniss, a los que ha atendido la conciencia, esto es 'experiencia vivida'.

Un análisis semejante lo encontramos en Martin Jay (2003), quien parte de los orígenes del concepto. Así, experiencia, proviene de experiri, que significa comprobar, forma de conocimiento derivada de la observación, de la vivencia de un evento o proveniente de las cosas que suceden en la vida. Por tanto la historia del concepto se alinea con el concepto de experimento. También en sintonía con lo anterior, Jay señala que erfahrung, contiene la palabra viaje y a su vez fahrt, se refiere a la duración temporal con posibilidades narrativas (el subrayado es mío). Esto es, emprendemos un viaje y un segundo término es erlebniss, que proviene de leben, esto es, vida, lo que sugiere una inmediatez vital que precede a la reflexión intelectual.

\footnotetext{
* No puedo dejar de señalar que todo esto también ha generado una suerte de "tecnocracia de la comprensión". Innumerables libros de autoayuda se han escrito con estos propósitos, aunque el origen del sufrimiento provenga de otras vías.
} 
La dificultad para referirse a la experiencia de sucesos dolorosos ha sido puesta de presente por diversos autores*. Es así como Primo Levy (2005, p.241) quien refiriéndose a su experiencia en los sucesos del Holocausto anota lo siguiente:

Quizá no se pueda comprender todo lo que sucedió, o no se deba comprender, porque comprender es casi justificar. Me explico: Comprender una proposición o un comportamiento humano significa (incluso etimológicamente) contenerlo, contener al autor, ponerse en su lugar, identificarse con él. Pero ningún hombre jamás podrá identificarse con Hitler, Himmler, Goebbels, Eichmann e infinitos otros.

Primo Levy concluye que la experiencia en el campo de concentración le permitió poder contar su historia ${ }^{\dagger}$. Plantea desde ya esa diferenciación entre los que han vivido un suceso y pueden hablar de él y los que no. Son experiencias de dolor, se habla y escribe también acerca de una herida social, pero preguntamos, ¿es posible que ese dolor trascienda a gran parte de la sociedad?

Destrucción, desfallecimiento y pobreza de la experiencia, son expresiones que reflejan su interés por el destino de la misma. Recurro a otro autor afín, Giorgio Agamben (2004), quien plantea que no se requiere de acontecimientos extraordinarios para destruir la experiencia ya que con la sola cotidianidad basta. Una lectura menos radical puede verse en el historiador, Dominick Lacapra, quien retoma a Nietzsche inicialmente para abordar el concepto:

\footnotetext{
* Ha sido bastante difundida y reelaborada también, la expresión de Theodor Adorno (1970) "Luego de lo que pasó en el campo de Auschwitz es cosa barbárica escribir un poema,..." (p.230). † Este pasaje de Primo Levi es tomado también por el Historiador Ian Buruma (2009, p.292) en su trabajo comparativo entre alemanes y japoneses durante la Segunda Guerra Mundial y particularmente frente al colaboracionismo concluye que a pesar del comentario de un testigo como Levi, ese salvajismo puede y debe explicarse porque esos hechos están en la memoria de los vivos y tanto la culpa como la vergüenza son asuntos de vital importancia.
} 
En última instancia, nadie puede escuchar en las cosas, en los libros incluidos, más de lo que ya sabe. Se carece de oídos para escuchar aquello a lo cual no se tiene acceso desde la vivencia; imaginemos el caso extremo de que un libro no hable más que de acontecimientos que estén más allá de las posibilidades de cualquier experiencia frecuente o incluso insólita, de que sea el lenguaje para expresar una serie nueva de experiencias. En tal caso, nada se oirá, pero se producirá la ilusión acústica de creer que donde no se oye nada, no hay tampoco nada. (Lacapra, 2005, p.60)

Analizando el sentido que pueda dársele a un determinado suceso, para dar cuenta de ellos a través de la escritura, Lacapra en su texto Escribir la historia, escribir el trauma, plantea algunos interrogantes, que si bien como él mismo lo anota no los resuelve en ese texto, me permito retomarlos porque son esclarecedores con relación al tema de la experiencia. El autor pregunta: ¿Cuál es la relación entre la experiencia diferenciada de agentes y sujetos del pasado, y la experiencia diferenciada de observadores y testigos secundarios? ¿Cuál es la relación entre la experiencia y las reivindicaciones de verdad y los juicios de valor crítico? (Lacapra, 2005, p.60).

En su siguiente texto, Historia en tránsito, amplía el concepto de experiencia y menciona que es un término muy invocado, pero escasamente teorizado tanto en la historia como en otras disciplinas y aquí vuelve a plantear otros interrogantes, los cuales me permito mencionar: ¿Qué es lo que escapa a la experiencia y no obstante pueda tener efectos experienciales? ¿Cómo interactúa con el lenguaje y con las prácticas significantes? ¿Qué clase de experiencias ayudan a soportar el trauma o a superar 
sus consecuencias? ¿Cómo puede la emoción sin límites, como en los casos de repetición compulsiva, desorientar, reorientar la experiencia y la vida social? ¿Cómo se modela y regula la experiencia a través de prácticas normativas como el ritual? ¿Cómo se relaciona con las posiciones e identidad del sujeto? (Lacapra, 2006, p.20).

De las definiciones del Diccionario Oxford se retoman las que más se aproximan a este trabajo: la observación real de hechos o acontecimientos considerada como fuente de conocimiento. También, lo que ha sido experimentado, los acontecimientos que han ocurrido y son de conocimiento de un individuo, de una comunidad o de la humanidad en su conjunto, ya sea durante un período determinado o en general. Es a partir de la última definición que se plantea la relación, sobre todo la valorización que se hace, entre aquellos que han vivido directamente el acontecimiento, y los que están vinculados a ellos por la memoria, por haberlo recibido a través de la herencia, o por encontrarse en una posición subordinada o que han recibido un legado.

La experiencia también es definida como el conocimiento resultante de la observación real o de algo por lo que uno ha pasado. El primer caso alude al tema del testigo, y el segundo, a la persona que ha tenido la experiencia, como a los que se identifican con ella o empatizan con ella. Podemos ir concluyendo, "Pasar por algo", es fundamentalmente, un proceso afectivo, no solo cognitivo.

Un aspecto que señala Lacapra que resulta importante es la duda que establece en cuanto a si el conocimiento por sí solo 
baste, para argumentar que la relación de una generación posterior con el pasado, -en ese sentido experiencial- crea lazos de identidad. Para ello establece la necesidad de contar con cierta respuesta afectiva proveniente de un sentimiento hacia la historia de un grupo y nuestra participación en él. Haber sido testigo secundario es otra dimensión de lo experiencial, aspecto que en nuestro caso lo relacionamos con la temática de la transmisión intergeneracional del trauma.

El papel de la afectividad como base para la empatía, es importante cuando se hace referencia al entumecimiento, la anestesia frente al trauma. De acuerdo con Lacapra (2006, p.21), los descendientes de víctimas y victimarios comparten una base empática* para afrontar los acontecimientos que enfrentaron a sus padres o sus ancestros, teniendo en cuenta que ambos recibieron una carga psíquica de acontecimientos de los cuales no son responsables, pero que sin embargo pueden sentirse obligados a responder.

Puede verse la importancia de este aspecto para el caso del conflicto armado en Colombia. Por ello nos preguntamos, ¿De qué manera se transforma ese dolor personal, íntimo y familiar a otro que atraviese el resto de la sociedad? Y ampliando aún más con la pregunta del jurista del sufrimiento, Madrid (2010): ¿qué puedo conocer de mi sufrimiento y qué puedo conocer del sufrimiento ajeno?

Es evidente que lo que se está abordando forma parte de la

\footnotetext{
* Esto se vincularía con el tratamiento inicial que dio referenciar Freud en el tema de la identificación, en Psicología de las masas y análisis del yo. (Freud, 1998, p.99). Freud también abordó la construcción de los lazos sociales y su vínculo con la justicia en varias de sus obras, particularmente en Tótem y tabú. Así mismo en el texto ¿Por qué la guerra?, carta que le dirigió a Einstein, trabaja el tema de las identificaciones y los lazos sociales.
} 
tensión entre lo público y lo privado de las memorias. Es la pregunta por el dolor en la sociedad que hace Alejandro Castillejo (2009) en el inicio de su texto.

¿Dónde ubicar el dolor y qué se hace con él frente al operativismo que conlleva los reclamos inherentes a la reparación? Retomamos a Susana Kaufman (2012), cuando nos dijo: Reconocemos los padecimientos como esquema interpretativo del sufrimiento humano, y nos advierte, que bajo el registro de lo cruel, se opaquen temas políticos en un proceso de sacralización de estos padecimientos.

¿Qué hace la sociedad con el dolor? Por un lado ignorarlos, y por otro, ubicar la mirada en las víctimas, como también en los perpetradores, al menos los más visibles. Es el tema del juicio hacia donde se dirigen las miradas y aquí al priorizar se deja de lado otros aspectos. El vínculo entre memoria y justicia es evidente, pero los análisis de su vinculación con los conflictos internos en los casos de Sudáfrica, Perú, El Salvador y Guatemala y lo que se ha venido observando en Colombia nos indica que es necesario tener una dimensión más amplia para involucrar otros referentes que vayan más allá del juicio a los perpetradores.

\section{LA TRANSMISIÓN}

Por otra parte, también vinculado al dolor, nos referiremos a ¿cómo se transmite este en la sociedad? Y ¿cómo se transmite en el plano de lo familiar y cuál es la articulación que se establece entre lo personal-familiar y lo social-político? ¿Cómo referirse al dolor social y llegar a utilizar términos como herida social, trauma cultural. Lo anterior se da en el plano de lo personal, de lo íntimo, lo subjetivo, lo social y lo político. Nos hallamos ante el recuerdo, como lo llama inicialmente Halbwachs y la concepción de la transmisión. 
Halbwachs se pregunta si lo que recordamos para nosotros puede ser igual para otros. Así mismo plantea "yo me acuerdo de aquello que otros me inducen a recordar". Puesto que los recuerdos son evocados desde afuera, y los grupos de los que formo parte me ofrecen en cada momento los medios para reconstruirlos, siempre y cuando me acerque a ellos y adopte al menos temporalmente sus formas de pensar. Aunque él mismo se pregunta: ¿Será así en todos los casos?

Aquí puede notarse cómo Halbwachs incluía el tema de la identidad e identificación con los grupos, aspecto que desde principios de siglo formó parte de la discusión, inicialmente de Le Bon y que luego fue retomado de modo crítico por Freud, en su artículo "Psicología de las masas y análisis del yo", publicado en $1921^{*}$. Halbwachs es tajante en afirmar que el individuo recuerda cuando asume el punto de vista del grupo y que la memoria del grupo se manifiesta y realiza en las memorias individuales. Así lo escribe: Completamos nuestros recuerdos apoyándonos en la memoria de los otros (p.35). Más aún:

$Y$ cuando el acontecimiento considerado ha agotado su efecto social, el grupo se desinteresa y solamente cuenta para el individuo afectado. Un duelo es importante como un hecho social, pero cuando pasa el tiempo sólo importa para el individuo afectado y se desvanece en la conciencia de la sociedad.(Halbwachs, p.158).

También con respecto al olvido menciona en otro aparte: Los grupos son capaces en cada momento de reconstruir su pasado, pero al mismo tiempo lo deforman. Muchos hechos los individuos

\footnotetext{
* A lo largo de los dos textos del sociólogo Maurice Halbwachs, Los Marcos sociales de la memoria, así como en La memoria Colectiva puede verse la incidencia de Freud. De hecho, el primero de los textos inicia con el análisis de sueños.
} 
lo olvidarían, si los otros no los conservaran para él (p.336).

La transmisión es considerada por Elizabeth Jelin (2002) como el proceso por el cual se construye un conocimiento cultural compartido, ligado a una visión del pasado. En otro aparte anota que la transmisión transita por tres vías simultáneas: la inercia social de los procesos de transmisión de tradiciones y saberes acumulados, por la acción de emprendedores de la memoria, quienes desarrollan políticas activas de construcción de sentidos del pasado, y en tercer lugar los procesos de transmisión entre generaciones.

Susana Kaufman en su artículo "Lo legado y lo propio, Lazos familiares y transmisión" (2006), considera que la transmisión es central como fundadora de la subjetividad, sentidos y filiación. Retoma los aportes que hizo primero Freud sobre el trauma, la neurosis de guerra y otros aspectos que fueron estudiados por psicoanalistas que le sucedieron. Destaca el papel que ha cumplido como emblemático para otros estudios los sucesos del Holocausto, al cual nos hemos referido, pero también la guerra civil española y otras situaciones vividas en América Latina, donde se observaron graves violaciones a los derechos humanos.

La autora aborda las manifestaciones traumáticas en las víctimas directas, como también en los interrogantes que hacían las generaciones siguientes, como fue lo sucedido en las vinculadas al Holocausto. Allí, se fue conformando un cuerpo teórico importante en los estudios de memorias, el cual trascendió el espacio familiar. Kaufman en su texto, mediante casos clínicos y otras observaciones, analiza los procesos implicados en la transmisión, en el marco de la clínica psicoanalítica; da cuenta de la afectación social que esos acontecimientos de terror producen. Además, se refiera a sus formas de expresión ya sea en el silencio, en las 
fracturas de los diálogos, pero también en actuaciones que a manera de demandas empezaron a gestarse como procesos colectivos, por parte de los familiares de las víctimas y que dieron lugar a organizaciones de familiares. Sobre estos, y sus procesos se revisará en otro apartado.

Jelin (2002) menciona tres propósitos de la memoria, los cuales revisamos en parte en este trabajo: En primer lugar, el reconocimiento del sufrimiento de las personas, en segundo lugar, el resarcimiento de las víctimas, esto es del orden de la justicia y en tercer lugar, el sentido pedagógico como es transmitir a las generaciones futuras lo sucedido.

Frente a esto último, Robin (2012), antes mencionada, nos pone en alerta, al señalar que en este auge de la memoria, se corre el riesgo de hacer "pedagogismo", el cual es uno de los aspectos que bloquea la emergencia de una memoria crítica. Esto es conjuntamente con una voluntad desenfrenada de transmitir, sin que se sepa lo que se quiere transmitir. Para esta autora, "deber de memoria" y "deber de transmisión" si no son problematizadas, son criticables. Lo que se transmite a despecho de la gente es el traumatismo, la ausencia de trabajo de duelo (p.367). Lo que discute la autora en ese capítulo es cómo se transmite y cómo, en muchas ocasiones lo que se presenta, particularmente a adolescentes, no les permite diferenciar la realidad de la ficción.

Esta situación la observamos claramente al inicio del proyecto Familias y Construcción de Memorias, sobre los casos de El Salado y Nueva Venecia* de dos familias. Al iniciar las entrevistas

\footnotetext{
* La investigación se desarrolló entre 2010-2012, abordando las memorias de las masacres de El salado y Nueva Venecia, ocurridas ambas en el año 2000.
} 
en sus casas, los más jóvenes recurrieron al video: "venga y le cuento, eso sucedió como aparece en el video".

Relacionado con esto, cita a Cathy Caruth (1995), quien argumentó que el debate acerca del Holocausto en los años 80 representó la posibilidad de inaugurar un debate acerca de una tercera vía para pensar la memoria. Frente a la memoria hegemónica construida por el aparato estatal o la memoria subalterna edificada por los sujetos no visibles de la historia oficial, la memoria sintomática es aquella que subyace a ambas figuras sin que haya sido resuelta o elaborada. Este tipo de memoria destaca la dimensión "residual" del pasado, ya que entiende este último como "resto" o "vestigio" de una pulsión no explicitada por los agentes sociales.

Un recorrido por las investigaciones que se han realizado en el tema, dan cuenta del valor del testimonio y lo que significa para las víctimas hablar del conflicto armado. Suelen mencionar su incapacidad de traducir en palabras lo ocurrido, de ahí que la expresión "no tengo palabras para describir lo que nos pasó", la escuchamos con frecuencia. Pero de modo intencional, también se encuentra la tendencia de no hablar a sus descendientes acerca de lo ocurrido, como ha sido reportado en numerosas investigaciones (Kaufman, 2006; Oberti, 2006; Garcia, 2012b, 2015). De entrevistas realizadas a víctimas del conflicto armado, recuperamos dos expresiones: "De los sucesos no hablo, por miedo". Pero también en otro caso: "No hablo por temor a que mi hijo mayor tome venganza" (García, 2012b)*.

\footnotetext{
* En el texto Rutas por la memoria (García, 2012b) se incluyen varios ejemplos tomados de las entrevistas realizadas en el proyecto Familias y Construcción de memorias.
} 
Lo anterior plantea algunos dilemas metodológicos y éticos que no siempre son contemplados. El silencio* tiene varias interpretaciones y como lo señala Susana Kaufman (2006) puede ser terapéutico, pero en general persiste la idea de que es muy negativo ejemplificado de modo contundente en la expresión: "hay que romper el silencio", visto este como fracaso.

No se contempla que también el silencio puede ser visto como un acto motivado hacia personas que como los investigadores/ as irrumpen en sus vidas, y más aún dentro de lo que Castillejo viene denominando extractivismo académico (2009). Pero el silencio y sus significados, también podemos verlo desde Bourdieu (2001), más allá de hablar, es necesario considerar el auditorio. ¿Es receptivo este al tema que estamos abordando?

Silencio y transmisión no se contraponen. El silencio se asocia a víctimas pasivas, que aunque utilicen términos como "dolor social", "herida social", se mantienen en el campo de lo privado. Pero esto no proviene solo de las víctimas o sobrevivientes, sino también de los dispositivos institucionales que se crean para abordarlas. Al respecto cabe mencionar lo anotado por Kimberly Theidon en su trabajo en Perú. Las mujeres para proteger a sus hijos hacían actos heroicos, pero luego la Comisión (se refiere a la Comisión de la Verdad en Perú) se enfrascó en una parte; esto es un dispositivo que se instala aparentemente para recuperar voces, pero a la vez silencia. ¿Sucederá igual en Colombia?

Al considerar el silencio como algo negativo, y en una inter-

* Desde otra óptica, una valoración del silencio en la literatura puede verse en el cuento de Juan José Millás (2006), Viva el silencio. 
pretación, si se quiere burda del psicoanálisis, se promueve la necesidad de hacer catarsis sobre los sucesos vividos. El afán por la memoria y la retórica del perdón mostrado en foros, congresos, lo que se consideran "casos exitosos" (comillas son mías), de otros países, está llevando a testimonios inducidos, puestas en escena, como lo reporta Castillejo (2009), en su trabajo de Suráfrica. Más recientemente (2015), revisa lo que denomina las producciones sociales del pasado violento (p.33), y dentro de este trabajo analiza algunas metáforas utilizadas también en nuestro país como "daño", "tejido social"* y en general lo que se enmarca dentro de la Justicia Transicional y que es revisado haciendo la analogía freudiana, como se refiere a la imaginación social del provenir.

La experiencia de dolor, del sufrimiento, puede obturar otras áreas. Lo anterior se vincula también a la concepción de víctimas, como seres pasivos, paralizadas por el dolor. Para los dispositivos gubernamentales, (pero también desde la academia) que se establecen, para ganar en compasión, es mejor que sean vistas de esa manera, así, como seres débiles beneficiarias de los programas asistencialistas que sujetas de derechos. Todo esto también ligado al papel de los colectivos en gran parte familias, que es lo que se trabajará seguidamente.

\section{LAS FAMILIAS Y LA TRANSMISIÓN}

La transmisión tiene en la familia un lugar privilegiado. Halbwachs (1994), ya mencionado, en su texto Los marcos sociales de la memoria, otorgó a la familia, conjuntamente con la clase social y la religión un papel importante en la organización de la

\footnotetext{
* En otro trabajo me refería a este aspecto, lo que llamé una "salubrización" de la violencia (García 2012a).
} 
memoria de los individuos. El papel de las familias como transmisoras de la cultura, las liga de modo directo al tema de la memoria.

Con relación a sucesos de violencia política que han devastado a nuestros países, se observa que para reclamar sus derechos, las personas empiezan a ser parte de organizaciones de víctimas, compuestas en su mayoría por familiares de los asesinados o desaparecidos. En todos estos procesos destinados a poner en evidencia los padecimientos, los crímenes y el desplazamiento de las poblaciones, son fundamentalmente los familiares, los portadores de las demandas. En Colombia, al igual que otros países del Cono Sur, así como de América Central, concretamente Guatemala y El Salvador, la organización de las víctimas de la violencia sociopolítica en procura de exigencia de justicia, forma parte de los escenarios visibles. Así, podemos mencionar a la Asociación Caminos de Esperanza Madres de la Candelaria, Asociación de Detenidos, Desaparecidos, ASFADES, Hijos e Hijas por la impunidad, Familiares del Palacio de Justicia, Asociación Colombiana de Familiares de Miembros de la fuerza pública, ASFAMIPAZ, Movimiento Nacional de Víctimas de Crímenes de Estado, MOVICE, entre otros.

Ser parte de estas organizaciones les permite ir construyendo ese Nosotros, que les posibilita sentirse en una comunidad que ha sufrido y vivido en carne propia un determinado suceso y que por tanto pueden dar cuenta de lo sucedido.

El vínculo entre la política y la familia en su dimensión biológica, centrada en los lazos de parentesco y relacionada con situaciones de violencia política, ha sido analizado por Judith Filc, en su 
texto Entre el parentesco y la política. Familia y Dictadura, 1997), donde mostró para el caso de Argentina, la utilización que hizo la dictadura de la representación tradicional de la familia y la concepción del país, formado como un conjunto de familias, gobernadas bajo un Estado-Padre*. También describe el proceso de las Madres de la Plaza de Mayo y la emergencia de nuevos discursos sobre la familia que fueron surgiendo a medida que la organización se consolidaba ante la falta de respuestas a sus peticiones ${ }^{+}$.

También Elizabeth Jelin $(2002,2007)$ se ha referido a las organizaciones donde el parentesco juega un papel clave. Una de las tensiones lo constituye el carácter valorativo que pueda tener la reconstrucción de historias que pueden ser utilizadas por unos y otros, las cuales pasan a tener mayor o menor peso de acuerdo a la posibilidad de haber "vivido en carne propia" las experiencias narradas. Aquí vemos nuevamente la vinculación con el tema de la experiencia antes abordado. La autora revisa la organización y construcción de las Madres de la Plaza de Mayo, las Abuelas y el Movimiento H.I.J.O.S y también se ha preguntado en varios de sus textos, por el tipo de ciudadanía que se construye desde estas afiliaciones y el tema de las exclusiones que esto pueda generar hacia quienes no comparten estos lazos.

¿Qué características tiene esta transmisión que se da en las familias y cómo incide esto en procesos políticos, donde se espera que se trascienda de los lazos familiares? Esa es una pregunta que nos hacemos para seguirla trabajando. Esto es la pregunta

* Cabe anotar las referencias, previas a la dictadura, a Eva Perón, como la gran madre de los argentinos.

† En otro texto, Filc (2001) analiza tres novelas latinoamericanas que dan cuenta de esta articulación, siendo el eje central la relación público-privada. 
por el papel que cumplen las organizaciones de víctimas donde el parentesco juega un papel clave.

Retomando a Halbwachs (1994) podemos ver que este autor tempranamente contempló este tema. Él señalaba las diferencias generacionales en el abordaje, tema trabajado posteriormente por otros de modo abundante, desde el Holocausto, sobre todo los autores que han escrito del trauma desde las guerras, así como desde otras perspectivas. Halbwachs, retoma a Goethe para describir los recuerdos de los ancianos y señala que los adultos absorbidos por sus preocupaciones actuales, pierden interés por todo lo que en el pasado no se conecte.

Anota además:

Si deforman sus recuerdos de infancia, ¿no es precisamente porque los obligan a entrar en los marcos del presente? Pero no es el caso de los ancianos. Estos, cansados de la acción, se desvían al contrario del presente, y se encuentran en las condiciones más favorables para que los acontecimientos reaparezcan tal cual tuvieron lugar. (Halbwachs, p.127)

Lo anterior permitiría explicar, en el caso de Colombia, el abandono en las luchas por las memorias en familias, cuyas condiciones de subsistencia son tan duras, que estos mecanismos de sobrevivencia les llevarían a dar una espalda al pasado o aún más articularse con políticas de memorias oficiales. Es por ello que en el caso de nuestro país donde la población afrodescendiente, indígena y habitantes de áreas rurales han sido los más afectados, la desigualdad persistente es una característica agendada desde las políticas públicas y sostenida por las mismas víctimas, que plantea interrogantes sobre el denominado proceso de paz.

A iguales conclusiones llegó en su trabajo en Perú, Carlos Iván 
Degregori (2001), así como Alejandro Castillejo (2009), en su trabajo en Sudáfrica y que considero importante para seguir retomando en nuestro caso, porque se vincula a la permanencia y no cuestionamiento de la desigualdad.

Lo anterior plantea algunos dilemas metodológicos y éticos que no siempre son contemplados. En el marco de lo que se ha llamado las "luchas por la memoria" (en las cuales la construcción institucional tiene un papel importante) la división que se establece entre quienes vivieron unos sucesos y quienes no, lleva a fragmentaciones en los procesos organizativos de las comunidades, como lo hemos visto en nuestros trabajos.

Apropiarse y argüirse de una experiencia ubica en un sitial de importancia a determinados grupos; de esta manera y retomando el tema de la experiencia, "ellos son poseedores de la verdad". Escuchamos la expresión en una de las entrevistas del proyecto Familias y construcción de memorias: "Ese man no puede decir nada porque el no estaba allá cuando pasó la masacre". Y para el resto de la sociedad que no ha sido víctima, pregunta inicial en este escrito, queda aún más relegada (García, 2012b).

Lo anterior, a pesar que nos encontramos en una suerte de tecnocracia de la paz y esto vista en perspectiva institucional nos muestra "la utilización" que se suele dar a las familias, acudiendo a su rol protector y responsabilizándola totalmente de la suerte de sus miembros y de la conservación de la paz. Todo va a descansar en la "buena convivencia", en el "desarme de los espíritus". De esta manera si revisamos lo acontecido en otros países latinoamericanos donde los dictadores acudían al lenguaje del poder, centrando en las familias la responsabilidad por un "Nuevo 
orden" era la propuesta exigida a estos colectivos, como nos lo relata en su texto Susana Kaufman (2006).

Esto no sucede solo entre los afectados directos del conflicto, sino también en la academia. La expresión "Yo sí puedo hablar de eso", nos acerca a este tema. En su artículo sobre la memoria de la guerra civil española, el historiador Pedro Ruiz Torres (2010), aclara: "Por razones de mi edad no viví la Guerra Civil, nací doce años después del conflicto. No puedo dar en consecuencia un testimonio directo de la guerra y carezco de experiencia personal de ella y de la inmediata postguerra". Y sigue contando lo que escuchaba de la guerra en los medios o en sus círculos familiares desde niño, en la adolescencia en la escuela o lo que escuchaba en los grupos de resistencia y luego se pregunta por la impronta de todo lo anterior y sus efectos retomando el tema del testigo, aspecto que no voy a abordar aquí.

\section{NOTAS FINALES}

Nos hallamos frente a una serie de tensiones relacionadas con el conflicto. Una característica que se encuentra en los procesos organizativos de víctimas y sobrevivientes de la violencia por razones del conflicto armado, como se planteó aquí es el familismo. Desde una perspectiva freudiana, es la exogamia lo que permite la construcción del lazo social, por tanto, reconoceríamos la debilidad de estas organizaciones en razón de esta característica.

Al mismo tiempo, frente a las políticas que se están instalando y las que se avecinan (posterior a las discusiones en La Habana), también esta condición plantea algunos interrogantes sobre el futuro de nuestro país. Tal como lo señala Castillejo (2015), frente a la economía de mercado en que está inserto nuestro proceso de 
paz (al igual que otros que se han dado en otros países), no se visualiza un interés en grandes transformaciones para Colombia. La revisión de lo observado en países de Centroamérica es un espejo importante para mirarnos.

Por el lado de las iniciativas de memoria de carácter estatal, el énfasis también está puesto en promover el uso de la memoria para hacer cierres del conflicto y para ello se recurre a los derechos culturales. Un ejemplo de ello es el caso que presentamos como reparación colectiva, la construcción de la Casa de la Cultura de El Salado (García, 2012b).

En este sentido, convenimos con la propuesta de Nancy Fraser (2008, p.39), cuando señala que las teorías de la justicia "deben convertirse en tridimensionales, incorporando la dimensión política de la representación, junto a la dimensión económica de la distribución y la dimensión cultural del reconocimiento". De acuerdo al ejemplo antes mencionado, se estaría privilegiando esto último. Pero, ¿cómo se abordan las demás dimensiones?

No hay un clima colectivo en la sociedad colombiana que nos lleve a la reflexión colectiva, sino que el proceso sigue sectorizado. Son experiencias de dolor, hay una herida social, pero, ¿cómo convertir ese dolor social en dolor político? Aquí retomamos a Doris Salcedo quien al utilizar el término de "herida social" sostiene lo siguiente: "Si bien la pena de familiares y víctimas es profundamente íntima, cuando la esencia de los eventos que la genera es política, la sociedad debe reconocer esta pena y su carácter colectivo". En estas poblaciones la recuperación de la memoria forma parte de lo terapéutico y es también un asunto de justicia. Pero no se trata de la recuperación como un hecho instrumental. 
Hay que considerar las causas por las que fue asesinado o desaparecido, esto es, las razones ideológicas, en donde el esclarecimiento de la Verdad tiene un papel fundamental. ¿Pero cómo reparar si de lo sucedido no podemos hablar? Lo que nos plantea nuevas interpretaciones al silencio y la emergencia de nuevas subjetividades.

Para cerrar, por ahora, consideramos que en los actuales momentos donde se plantea el postconflicto, se hace necesario un diálogo que vincule a la Academia con los movimientos sociales, con la intención de revisar con una mirada crítica las iniciativas de memorias. Es posible que una gran parte de la Academia imbuida como está en perspectivas de sobrevivencia, aliada de políticas sin reflexión, estén más centradas en el abordaje de las consecuencias del conflicto armado que de las causas. También cabe anotar, que la mayor parte de los estudios que abordan a las familias, lo hacen con los colectivos organizados de víctimas o víctimas registradas, pero, ¿que sucede con aquellas personas que por distintas razones no se inscribieron en los formatos o aun más no se autorreconocen como tales?

Por eso, cito a José Antonio Pérez (2010), quien se refiere a Manuel Reyes Mate (2009), al recibir el premio de literatura 2009, en el capítulo de su obra La herencia del olvido. Se refiere así a las víctimas:

Durante siglos se han hecho invisibles; ahora se han hecho presentes, pero sólo sabemos decir de ellas que hay que acompañarlas, conocerlas, venerarlas o repararlas. No nos decimos a pensarlas políticamente, porque eso significa poner en tela de juicio una lógica política que sigue presente, dispuesta a avanzar cobrándose nuevas víctimas. Pensar 
políticamente las víctimas significa repensar la relación entre política y violencia, asunto sobre el que pasamos de puntillas.

Concluimos que es la política la asignatura pendiente en gran parte de la Academia.

\section{REFERENCIAS BIBLIOGRÁFICAS}

Adorno, T. (1970). Crítica cultural y sociedad. Barcelona: Ariel. Agamben, G. (2004). Infancia e historia. 3ra ed. Buenos Aires: Adriana Hidalgo Editora.

Benjamin, W. (1967). Sobre algunos temas en Baudelaire. Ensayos escogidos. México, Ediciones Coyoacán, S. A. de C. V.

Bourdieu, P. (2001). Qué significa hablar. Economía de los intercambios lingüísticos. Madrid, Ediciones Akal, S.A.

Buruma, I. (2009). El precio de la culpa. Cómo Alemania y Japón han enfrentado su pasado. Barcelona: Duomo ediciones.

Castillejo, C. A. (2005). Las texturas del silencio: Violencia, Memoria y los Limites del Quehacer Antropológico. Empiria. Revista de Metodologías de las Ciencias Sociales, 9, 39-59.

Castillejo, C. A. (2009). Los archivos del dolor. Ensayos sobre la violencia y recuerdo en la Sudáfrica contemporánea. Bogotá: Uniandes CESO, Departamento de Antropología.

Castillejo C. A. (2015). La imaginación social del provenir: reflexiones sobre Colombia y el proyecto de una Comisión de la verdad. Buenos Aires: Clacso.

Cepeda, I. (2007). Memoria histórica: De víctimas a ciudadanos. En: Programa de las Naciones Unidas para el Desarrollo. (PNUD). Disponible en: www.acnur.org/fileadmin/scripts/doc. php?.file=fileadmin/news_imponted_file/COL_2125

Congreso de Colombia (2011). Ley de víctimas y restitución de tierras. [Ley 1448 de 2011] recuperado de http://www.alcaldiabogota.gov.co/sisjur/normas/Norma1.jsp?i=43043 
Degregori, C. I. (2001). Desigualdades persistentes y construcción de un país pluricultural. Reflexiones a partir de la CVR. Recuperado de: http://red.pucp.edu.pe/ridei/temas/desigualdades-persistentes-y-construcción-de-un-país $\neg$ pluricultural-reflexiones-a-partir-del-trabajo-de la-cvr/

Filc, J. (2001). Espacios alterados: La calle y el hogar en tres novelas de la dictadura en el Río de la Plata. Estudios interdisciplinarios de América Latina y el Caribe, 12(2). Universidad Nacional de General Sarmiento, Buenos Aires. Recuperado de: http://eial.tau.ac.il/index.php/eial/article/view/982/1017

Filc, J. (1997) Entre el parentesco y la política. Familia y dictadura, 1976-1983. Buenos Aires: Biblos.

Fraser, N. (2008). Escalas de justicia. Barcelona: Herder.

Freud S. (1999). Psicología de las masas y análisis del Yo. Tomo III. Buenos Aires: Amorrortu, Editores.

Freud S. (2000). ¿Por qué la guerra? (Einstein y Freud). Tomo XXII. Buenos Aires: Amorrortu, Editores.

García-Acuña, Y. (2012a). Las víctimas del conflicto armado en Colombia frente a la Ley de Víctimas y otros escenarios de construcción de memorias: Una mirada desde Foucault. Justicia Juris, 8(2): 74-87.

García-Acuña, Y. (2012b). Rutas por la memoria. Voces de Nueva Venecia y El Salado. Barranquilla: Ediciones Universidad Simón Bolívar.

García-Acuña, Y. (2015). From the studies of violence to memories: the construction of victims and its articulations with the state. In Cante Fredy \& Quehl Hartmut. (2015). Hanbook of Research and Transitional Justice and peace Building in Turbulent regions. Felsberg Institute-Universidad del Rosario.

Halbwachs, M. (1994). Marcos sociales de la memoria. Barcelona: Anthropos, Facultad de Ciencias Sociales de la Universidad de Concepción. 
Halbwachs, M. (2004). La memoria colectiva. Zaragoza: Prensas universitarias de Zaragoza.

Jay, M. (2003). La crisis de la experiencia en la era postsubjetiva.

Santiago de Chile: Universidad Diego Portales.

Jelin, E. (2002). Los trabajos de la memoria. Madrid: Siglo XXI Editores.

Jelin, E. y Kaufinan, S. (2006). Subjetividad y figuras de la memoria. Madrid: Siglo XXI Editores.

Jelin, E. (2007). Familiares, víctimas y ciudadanos: las luchas por la legitimidad de la palabra. Recuperado de: http://www. scielo.br/pdf7cpa/n29/a03n29.pdf

Kaufinan, S. (2006). Lo legado y lo propio. Lazos familiares y transmisión de memorias. En: Jelin Elizabeth y Kaufman Susana, Subjetividad y figuras de la memoria. Madrid: Siglo XXI Editores.

Kaufinan, S. (2012). Construcción de memorias, procesos subjetivos y fracturas de transmisión. Trabajo presentado en el III Congreso Internacional en Violencias: Memorias del conflicto armado. Barranquilla: Universidad Simón Bolívar, Marzo 15.

Lechner, N. y Güell, P. (2006). Construcción social de las memorias en la transición chilena. En: Jelin Elizabeth y Kauftnan Susana, Subjetividad y figuras de la memoria. Madrid: Siglo XXI Editores

Lacapra, D. (2005). Escribir la historia, escribir el trauma. Buenos aires: Nueva Visión.

Lacapra, D. (2006). Historia en tránsito. Experiencia, identidad, teoría crítica. México: Fondo de Cultura Económica.

Levy, P. (2005). Trilogía de Auschwitz. Si esto es un hombre. La Tregua. Los Hundidos y los Salvados. Barcelona: El Aleph Editores. 
Madrid, A. (2010). La politica y la justicia del sufrimiento. Madrid: Trotta.

Martínez-Rodríguez A. (2011). La Paz y la memoria. Madrid: Los libros de la catatrata.

Millas, J. (2006). Viva el silencio. Madrid, HKlickowski-ONLYBOOK, S.L.

Oberti, A. (2006). La memoria y sus sombras. En: Jelin Elizabeth y Kauftnan Susana, Subjetividad y figuras de la memoria. Madrid: Siglo XXI Editores.

Ospina, W. (2001). Si huyen de mí, yo soy las alas. En: Ospina William. Los nuevos centros de la esfera. Bogotá: Aguilar.

Pécaut, D. (2013). La experiencia de la violencia: Los desafios del relato y la memoria. Medellín: La Carreta Histórica.

Pérez, J. (2010) La memoria de las víctimas del territorio del país Vasco: Un proyecto en marcha. En: Rivera, A. y Carnicero, C. (Eds) (2010) Violencia política: Historia, memoria y víctimas. Maia, Madrid: Instituto Universitario de Historia social. Valentín de Foronda. CUPV/EHU.

Robin, R. (2012). La memoria saturada. Buenos Aires: Waldhuter editores.

Ruiz, T. P. (2010). Los discursos de la memoria histórica. En: Valencia, España: Publicaciones de la Universidad de Valencia. Riaño, P. (2005) Los talleres de la memoria con población desplazada en Colombia. En: Revista Historia antropología y fuentes orales, 34, 81-96.

Theydon, K. (2007). Género en transición: sentido común, mujeres y guerra. Bogotá, Colombia: Análisis Político, 60, 3-30 Traverso, E. (2007). El pasado, instrucciones de uso. Historia, memoria, política. Madrid: Marcial Pons. 